\title{
Exploring Functionings and Freedoms in Dubai
}

\begin{abstract}
The period from 2006 to 2013 in Dubai was an era of hyperurbanization and rapid growth. Disability policies, programs, and engagement with people with disabilities were occurring in tandem with the rapid modernization of the city-state. How did these changing physical, social, and institutional contexts impact the lives of people with disabilities across the two separate but interconnected domains, basic functionings and basic freedoms? This time period was also notable for the lack of a comprehensive approach to disability policy and accessibility reforms. Interview respondents indicated that approaches were fragmented and there was a clear gap between what the public sector agencies said they were doing and the type of services and opportunities people with disabilities and their families actually received. This highlighted the importance of advocating for specific actions and policies to ensure the provisions outlined in Federal Law No. 29 and the UN Convention on the Rights of Persons with Disabilities were being achieved.
\end{abstract}

Keywords Policy design • Policy implementation • Contemporary history of disability in the Middle East $\bullet$ Public policy in the UAE

- Inclusive community development $\bullet$ Accessibility $\bullet$ Exclusion

- Urban policies and programs $\bullet$ Participation $\bullet$ Nondiscrimination

(C) The Author(s) 2020

V. S. Pineda, Building the Inclusive City, https://doi.org/10.1007/978-3-030-32988-4_5 


\section{Dubai Forms a Foundation for AcCess And InClusion}

The pressure of rapid economic growth has benefits but also costs and consequences for persons with disabilities. This chapter explores in greater detail the empirical findings and observations I collected through fieldwork in Dubai during the period 2006-2013. This was an era of hyperurbanization and rapid growth. Disability policies, programs, and engagement with persons with disabilities developed in tandem with the modernization of this city-state. What characterized access during this period of transformation? How did the changing physical, social, and institutional context impact the lives of persons with disabilities across two separate but interconnected domains, basic functionings and basic freedoms? In the next two chapters, we will explore how these factors changed between 2006 and 2013, as well as in the subsequent period after the passage of the Dubai Disability Strategy of 2014.

From 2006 to 2013, I studied and participated in the development of the policies and programs that would impact the lived experience of persons with disabilities. The chapter is broken into two complementary sections benchmarking basic functionings and basic freedoms. The benchmarking foregrounds fragmentation but also tremendous potential for continued growth. I begin with an assessment of key findings in four policy areas that I will refer to the four basic functionings: health, rehabilitation, education, and employment. Then I will transition to an assessment of key findings in five policy areas that I will refer to the five basic freedoms: public participation, independent living, awareness raising, access, and mobility.

\section{Benchmarking Basic Functionings in Dubai}

Given my earlier discussion of the Capability Model of Disability (CMD) and the context of disability rights in the UAE, I now turn to elaborate on my disability rights framework with a discussion on basic functionings. ${ }^{1}$ As described in Chaps. 2 and 3, I adopt the term from Amartya Sen's important work on development. According to him, basic functionings are the actual achievements of the individual, for example, obtaining a university

\footnotetext{
${ }^{1}$ The titles used for this and the following chapter are a reference to Robert Imrie's 1996 work, Disability and the City. This was an influential and pathbreaking book that very much inspired me and my own research. uk.sagepub.com/en-gb/eur/disability-and-the-city/ book 229509
} 
degree or competing in the Special Olympics. ${ }^{2}$ Sen's Capability Approach (CA) framework reveals the limitations of overemphasis on income and wealth when people's capabilities (i.e., opportunities) and functionings (i.e., activities) are unattended. With respect to my model, Sen's capability relates to the CMD through an emphasis on sets and bundles of functionings from which a person is able to freely choose between various alternatives at their disposal. Mitra expands Sen's Capability Approach to touch upon the various ways in which disability can be defined conceptually. CA highlights two nuances related to issues in disability - deprivation of capabilities and deprivation of functionings. These two concepts run parallel to our basic freedoms and basic functionings that respectively seek to address capability deprivations.

\section{Health and Rebabilitation}

The UAE has a dual system of healthcare whereby federal and local agencies compete and complement each other in service provision. Since 2006, the UAE has invested considerable resources in developing and providing health services to citizens and foreign workers in the UAE. In 2008, Dubai issued a mandatory health insurance system for citizens and resident aliens (Emirates 2008, 20). This is not a single-payer plan, but rather a mandate to ensure that a private health insurance market is viable. The National Strategy Brief (Office 2006) identifies developing the health sector as a strategic development goal for the UAE. An example of this in practice is the rise in the number of facilities. In 2006, there were 225 public hospitals and clinics for the entire nation. By 2019, there 268 hospitals and clinics in the Emirate of Dubai alone. ${ }^{3}$

Rehabilitation services (physical, occupational, educational, social, psychological, and vocational services) are offered to persons with disabilities in the UAE. These rehabilitation services are provided through three main channels: primarily through the government-run rehabilitation centers linked to hospitals and medical establishments, secondarily through the specialized support and rehabilitation centers, and finally through the adaptive sports programs offered by the Dubai Club for People of Determination.

\footnotetext{
${ }^{2}$ NOTE: Find note/example of Pablo Pineda, or other Special Olympics athletes who also completed a university curriculum.

${ }^{3}$ Dubai health authority, Google Maps, and public records were used to estimate the total number of health facilities with the name hospital or clinics in the Emirate of Dubai.
} 
The UAE has the sixth-highest rate in the world of children born with genetic defects (McMeans 2010). According to Dukmak (2009), a researcher at UAE University, there is a serious and growing need for coordination of services, resources, and program sharing in the field of rehabilitation. Many parents feel embarrassed for having a child with a disability and some would rather deal with the problem on their own privately than expose their family to scrutiny by the state (McMeans 2010). According to focus group respondents I interviewed, "There are a lot of people who try to hide it... to be able to face it (in a traditional society) and come out in public is a very brave thing to do." A government employee and academic that I interviewed stated, "as a mother of a child with special needs, I can say that learning to raise a child with a disability in the UAE can be a daunting task. Parents should get help from each other, from the doctors, from social workers, from psychologists on how to work with a child with a handicap." But oftentimes these parents do not know where to go.

\section{Centers Provide Specialized Supports}

On October 5, 2009, I visited the Al Noor Training Centre for Persons with Disabilities. By this time, the Al Noor Training Centre had celebrated 28 years of service, and like most centers I visited in the region, was started by a leading UAE family at the time who had a disabled child. I started by meeting with Deepika, a 29-year-old Fulbright Scholar and Auditory Specialist from India who had been working at the center for the past 3 years. She told me that she came to the center to perform important services as a speech-language pathologist and to conduct some of her own research. She told me that most families face similar challenges in terms of providing their children with the right help and that the biggest problem is access to necessary services. There is also a lack of knowledge in the community of what services are available. Deepika felt that this lack of knowledge and the lack of access stems from societal attitudes in the Gulf. She stressed that such attitudes also affected the center's ability to generate funding and obtain stronger community solidarity.

Mrs. Khatib has been at the center for 11 years and has a background in physical therapy. She points out that Dubai is unique in that over $80 \%$ of the population are not citizens but foreign workers. This very large yet "fluctuating" group includes households that are touched by disability. She stressed the need to have Federal Law No. 29 specifically address this population and delineate the rights of non-nationals with disabilities. She admits that this type of policy and reform would be "uncharted waters." 
Mrs. Khatib noted that extending the law to foreign nationals would also be a stretch because to her knowledge, there was no specific disability policy elaborated in Federal Law No. 29 in any realm of society. According to her, this was urgent because although the law exists on paper, there is still no defined status or specified regulations to enforce. Because of this, she feels that every aspect of Federal Law No. 29 in relation to disability rights is still left open to interpretation. She stressed that unless standards are defined and regulations are developed, the people with disabilities and service providers would not be able to make progress.

\section{Rashid Pediatric Center for Rehabilitation}

The next week, on October 12, 2009, I visited Rashid Pediatric Center for Rehabilitation and met with a head teacher with responsibility for both programming and administration. The walls are covered with art, paintings, and photos. The main hall at Rashid is full of cheerful and bright primary colors. Rashid Pediatric Center was named after the former Ruler of the Emirate of Dubai, Sheikh Rashid Al Maktoum. The center had first caught my eye in 2007 during my first visit to the UAE when I picked up a copy of a comprehensive magazine on disabilities called Rashid. I told the head teacher that I first picked up "Rashid Magazine" on board an Emirates Airlines flight in 2007 and was happy to learn about their efforts. The center has 140 students and 85 staff members. It is a multicultural center that represents over 35 nationalities and accepts students aged between 3 and 20. The head teacher said that the center offers therapy and classes in English and Arabic (as well as Urdu and some other languages). The maximum class size is eight students. The head teacher indicated that the center faces a common issue that affects other similar centers in Dubai; that capacity and resources are stagnant so there is no room for new students or expansion of services due to a lack of funding. According to the center's staff I spoke with during my visit, there are hundreds of children on the waiting list whose needs cannot be met.

The center also has a "best buddy" program where students from general education schools come by after their classes to play games and socialize with the children at the center but she mentioned that there were not many Rashid students that visit regular classrooms. Each Rashid student has an Individualized Education Plan (IEP) that is assessed on a regular basis and modified if necessary. Therapy makes up the majority of each student's curriculum as most of the students at the center have a "cognitive (learning) disorder." 
During my interview, I learned that the school did not have a standardsbased curriculum and that the Ministry of Education provided no clear oversight on learning. Focus group participants complained that Rashid and other centers couldn't offer recognized diplomas. My host mentioned that the average developmental age of the students is eight years old and that academics do not play a major role in the curriculum, although it is provided to those that can "process it." The head teacher noted that her curriculum focuses on socialization. I found it strange that a group of children with ages that range from 8 to 15 who had hearing impairments were studying "what things are made out of." I asked why they are studying this if they had a hearing impairment and not a cognitive impairment. Though she couldn't answer, the head teacher mentioned that about a fifth of the 29 students have no inherent cognitive impairments but are at Rashid because of neglect, abuse, or other reasons.

\section{Challenges to Rehabilitation}

According to the head teacher at one of the country's leading pediatric rehabilitation centers, many initiatives in Dubai are launched with too much fanfare and too little follow-through. This excitement builds up when members of the Royal family endorse an initiative. One interview respondent stated, "Important things are discussed but too often are not realized. The inactivity and lack of action are endemic." The head teacher echoes this and states that efforts are inconsistent, and "the lack of tangible effort on behalf of the 'backers' leads most new initiatives to lose momentum, there are too many shortcomings across multiple levels." The process of achieving social inclusion is missing. She summarizes the predicament that the centers face as follows: "There's a will, but no way."

An example she gave was related to building codes. Architects visited Rashid a few years ago and came to explain the new building regulations that were being developed to guarantee access. She was frustrated that she never found out what happened from that visit. According to her, there is still no regulation or standardization of building codes. As such, most efforts in the field of disability rights become "unsustainable initiatives." She mentions that this is due to the fact that the law has not been developed-it does not have regulations and still needs to be applied.

The head teacher I spoke with believes the failure in application is due to the lack of administrative and coordinating capacity of the Ministry of Social Affairs. The Ministry of Social Affairs regulates and supervises the activities including working hours of the centers. She cited that the school 
days are entirely too short and as head teacher, she can only keep students between 8:30 am and 1:15 pm despite having ample buses, drivers, and assistants that would allow for younger and older students to be dismissed at different times, which, for example, would allow older students to stay at the center for a longer period than younger students.

\section{Athletic Training and Sport Rehabilitation}

There is a vibrant community of athletes with disabilities that receive support, train, and compete in adaptive sports programs. The Dubai Club for Special Sports (now called the Dubai Club for People of Determination) serves as the primary meeting point for persons with physical disabilities to get together and develop their self-confidence and self-esteem. During an interview I conducted in 2009, Majid Al Osaimi, the Secretary-General of the sports-based UAE Federation for People of Determination, said that

The UAE has participated in every Paralympics since 1992, earning 19 medals including 4 gold medals. The dominant approaches to disability rights are through services and programs that are based on rehabilitation and sports. There is a strong prejudice toward treating people with a disability as being sick and needy. We want equal treatment and the basic services to improve our position in society. In sports we are champions and have brought back medals from the Beijing, Athens, and Atlanta Paralympics.

He has since gone on to serve on the Dubai Higher Council for People of Determination, and to represent the UAE in sports and human rights conferences raising awarness of disability rights.

Rashid Saeed, a young 23-year-old man with cerebral palsy, has virtually grown up benefiting from the services offered at the Dubai Club where he serves as an Ambassador for Adaptive Sports and Health. Besides improving his physical and coordinating skills, this offers Rashid the opportunity to travel and attend competitions in a variety of sports.

\section{Jumpstarting Inclusive Education}

According to official government statements I reviewed between 2007 and 2014, the UAE implemented a number of programs to establish an advanced, up-to-date educational system in keeping with current educational technologies and advancing students to higher levels of education (Emirates 2008, 19; KHDA 2014). These efforts indicated a commitment of the State to be responsive to the needs of students with 
disabilities. According to the Human Rights Commission Report generated by the United Nations, people with disabilities are entitled to the same rights as others but are being denied those rights by many private schools in the UAE. However, prior to 2009 efforts were sparse and guidance was very basic. Between 2009 and 2013, a slow but steady effort by the Knowledge and Human Development Authority (KHDA) worked to assess and address significant gaps. Efforts by the KHDA focused on outreach, education, accommodations, and on undertaking cost assessments of inclusion. Unfortunately, during this period the patchwork approach to the implementation of Federal Law No. 29 led to schools and charities that did provide meaningful education and support services to persons with disabilities to become heavily oversubscribed.

\section{Inclusive Education in the UAE}

Public and private schools in the UAE and in Dubai have divergent pathways to inclusive education. Federal Law No. 29 assures the rights of persons of determination to receive an equal education.

Special Education Reforms began unfolding in earnest in 2008-2009. By 2009, national students with different types of disabilities were starting to be enrolled in regular public schools. ${ }^{4}$ However, the developed policies designed to address service gaps that most private and public schools in the UAE faced in this period were ill-equipped to accommodate a broader number of children with physical, sensory, development, and/or intellectual disabilities on a consistent basis. Special education is provided for a select group of students in select public schools. Only specific physical, neurological, developmental disorders or intellectual disabilities, or high achieving students would be accommodated through pilot programs. In the period between 2009 and 2012, these students started to benefit from a general education classroom experience but not in a way that was comparable to their non-disabled peers.

Most of these early reforms were being led by Ms. Noura Ibrahim Almarri, the Director of the Ministry of Education's Department of Special Education in cooperation with two of her colleagues from the department. The Special Education Department at this time set the foundation for establishing more inclusive programs. According to the 2009

\footnotetext{
${ }^{4}$ In 2010, the Ministry drafted a new set of standards for inclusive education that set off a series of changes in local policy. Authority, U. M. (2010). UAE Yearbook 2010. UAE Yearbook. N. M. Council. Abu Dhabi, UAE Media Authority: 230.
} 
Special Education Standards, ${ }^{5}$ the focus on inclusive (as opposed to "special") education is reflected in the department's vision and mission statements. The Department, however, was very small, understaffed, and underfunded according to Ms. Noura Ibrahim Almarri. She does not have a staff to help the schools deliver on their mandates.

By 2010, the Ministry of Education's Department of Special Education was tasked to plan, execute, follow, and supervise inclusive and special education programs with trained personnel. The department's three staff members had to ensure that all students received an appropriate, individualized education based upon their strengths. Although the department developed standards and provided awareness of and capabilities to implement Federal Law No. 29, students with disabilities were routinely being denied admission to public and private schools and encountered barriers to employment or tertiary education. The Ministry sought to provide educational assessments and training of teachers in diagnosis and early intervention. By 2012, these goals were not being realized due to limitations in executive leadership, institutional capacity, and lack of broad partnerships and participation from targeted groups. According to participating teachers, these early initiatives were ineffective. The first set of guidelines did not sufficiently ensure that both general education and special education teachers would share the responsibility of educating students with disabilities.

One of the major institutional challenges I encounter between 2006 and 2012 is that out of the thousands of public and private schools in the UAE, there are only a handful of schools that accept students with disabilities. They also tend to add additional costs and pass on the added expenses to the disabled child to accommodate, as one interviewee suggested these expenses were "for the expense and maintenance of their special need." Schools engaging in such discriminatory practices and are in clear violation of Federal Law No. 29 and the Convention on the Rights of Persons with Disabilities (CRPD).

\section{Ensuring Dignified Work}

By 2008, the UAE had one of the highest percentages of imported labor in the world; 250,000 employers employ 3,113,000 foreign workers of more than 200 nationalities (Emirates 2008, 16). The number of persons with disabilities in the workforce was unknown; statistics were not kept so

\footnotetext{
${ }^{5}$ The Special Education Standards were revised in 2017. This is discussed in more detail in the conclusion of this chapter.
} 
progress would not be measured until better statistics could be developed. According to several interviews corroborated by focus groups conducted between 2009 and 2012, the employment rate for people with disabilities, however, has steadily increased and attention from both the public and private sectors has increased. A few leading companies are seeing positive results by deploying best practices in inclusive employment.

\section{Frustrated Voices on Employment}

Morad Ali Shadeed is a wheelchair user and Jordanian national who lives and works in Dubai. His employment is full-time and his remuneration is lower than his counterparts who work similar hours and similar jobs. Additionally, his office is on the second floor in a building without an elevator and he has to drag himself up and down the flight of stairs each day. According to Morad, his colleagues and his employer commend him for his efforts and his work, but nonetheless he feels that "things are not right. I will never get a promotion or advance at the company." He has sought other employment but has not been able to secure anything so according to him, "I am just going to have to shut-up and keep working." This experience of discrimination based on disability was not unique to Morad. Masoud M. Al Khouri also has felt it at his work. Masoud is a manager with a hearing impairment and notes that too often he is passed up for promotions. He confessed that he works hard and during our second focus group held at the Dubai School of Government, he confessed that he felt he was being discriminated against by his employer on account of his disability.

According to a political scientist who in 2009 served as a professor at the Dubai School of Government, there is a long way to go for the UAE to effectively regulate employment for persons with disabilities. One of his students, Amal El Robee, agreed. Amal conducted a national study on the vocational aspirations and realities of persons with disabilities in the UAE, the Ministry of Labor had not contributed in any meaningful way to developing or implementing employment protections for persons with disabilities. In speaking with individuals on the topic I noticed that most respondents seemed to note that although there are no explicit legal restrictions limiting the employment of persons with disabilities, the lack of protections again discrimination based on disability in effect limits their equal participation in work. However, discrimination on the basis of disability goes against Articles 16 and 18 of Federal Law No. 29 and also Article 20 of the UAE Constitution. The constitution stipulates that the state, "shall furnish the appropriate facilities for that by providing legisla- 
tions protecting the rights of the employees" (Bitar 1971). One UAE resident with paraplegia stated, "We need specialist employment services that go beyond mandating quotas to be included in the mainstream labor market." Additional attention with a clear strategy was needed in this period to protect persons with disabilities from neglect and abuse.

This is well described by the director of a Dubai center that provides employment readiness training. She shared a story of the real opportunities that people with disabilities have, "Much positive momentum exists, and there is fertile ground from which to build off. The government agencies seem supportive, there is willingness. But I just don't have the way to fully carry out real changes." When asked to elaborate, she just said, "there is a will, but there is no way. It's a complex issue and there is often no progress." She was talking about the social and institutional barriers that limit people's choices and by doing so limit their freedom to take action. Like the previous assessments on basic functionings, I next turn to look at a category of policy areas in the domain of basic freedoms.

\section{Benchmarking Basic Freedoms in Dubai}

Basic freedoms highlight the underlying structures that facilitate an individual's choice and agency. They support an individual's ability to participate on an equal basis with others in society. Basic freedoms elevate the inherent dignity of the individual. The notion of freedom is that you don't have to think about negotiating your existence or your preferences. Basic freedoms grant you the right to act upon the world, be seen, enjoy, and shape your environment (whether it be in the physical world or through accessing digital content online). Freedom includes such basic rights as the opportunity to board a train or be able to use a sidewalk to avoid risking your safety negotiating oncoming traffic on the street. Freedom includes the right not to be discriminated against.

The literature on basic freedoms exists in the context of human rights, development, and disability justice. Vizard et al. (2011) attempt to bridge the conceptual gaps between Sen's capability approach and an international human rights framework to inform the ways these concepts can have practical public policy applications. For example, human rights inform "processes of ethical recognition and political campaigning, integration into public policy, and broader processes of social transformation that affect expectations, behavior and choices...[and integration of] human rights standards and principles into broader public action strategies" (10). 
Vizard et al. highlight the need for state evaluation with respect to results achieved in international obligations and policy evaluation to measure compliance with human rights laws. The authors draw on Sengupta's mode of the Right to Development $(2002,2004)$. This model's application to the expansion of substantive freedoms via internationally recognized human rights standards sets important new mechanisms in place for measurement and evaluation of development (Sengupta et al. 2005).

The following sections highlight fieldwork findings around basic freedoms and illustrate some of the important early factors that would develop between 2006 and 2013 and become prerequisites to creating what Dubai is today. This section enables an exploration of the choices that individuals with disabilities have with respect to five domains of basic freedoms: participation, awareness, mobility, independent and community living, and accessibility.

\section{Public and Political Participation}

During the period 2006-2012, the UAE began a process of gradually opening political participation. Initially, the Federal National Council (FNC) began to increasingly acquire legislative and representative legitimacy. The State adopted a clear timetable of gradual steps so that each stage of opening participation could be evaluated independently. Tellingly, during this period the Services for Educational Development, Research and Awareness for Inclusion, also called SEDRA, a non-profit group supporting persons with disabilities, supported the election campaign of a woman with a disability to the FNC. Although she did not win, it served as a statement that women with disabilities could play a role in political and public affairs.

In the UAE, associations, clubs, civic and volunteer networks, and trade councils for expatriates are the primary means for realizing political and public participation. These activities were heavily regulated and are seen as strengthening social cohesion among the various and diverse local and foreign residents of the emirate (Emirates 2008). Public and political participation of persons with disabilities in this period was weak and according to an Emirati named Ahmad, "this lack of meaningful participation in the decisions that affect us is keeping us stuck." Ahmed's view was echoed by others including those from the focus groups who stressed that the absence of a vibrant community of non-governmental organizations impacts the development of disability rights. Participants a series of focus groups I conducted in 2009 at the Dubai School of Government included parents and professionals as well as persons with disabilities. Parents and 
professionals stated that they wanted to participate more meaningfully in policy development, by sharing their opinions and experiences with the Ministry of Social Affairs. Participants wanted a more open and transparent manner to engage and felt left out and ignored. Parents particularly felt frustrated by the lack of clarity, professionalism, or simply a response to an inquiry. Many parents talked about how they sought out support or answers to basic questions to no avail.

Experienced residents like Mouna, a special education teacher and mother of a child with cerebral palsy, did not hold out much hope for rapid change in this area as she indicated that her opinion was irrelevant to the authorities. She stated, "our experiences are not important to them." She indicated that she felt ignored by the people working in the ministries. They want to attract consultants from abroad because they assume anything developed in the UAE would be based on old policy documents, old language, and old approaches. "This is absolutely not true...there are a lot of people like me that could contribute, but have gotten tired of fighting."

Specifically, according to Mouna, "the lack of voice, capacity, and power of persons with disabilities limits what can be accomplished here." She said that most efforts undertaken in Dubai were fragmented, meaning that most initiatives are either ad hoc proclamations by Sheikh Mohammed or key members of the ruling family. Those initiatives rarely engaged substantively with persons with disabilities and where they did, they were often uncoordinated efforts of parents of children with disabilities. By 2012, adults with disabilities had not yet claimed any meaningful role in developing and shaping policy. A fact that would soon begin to change.

\section{About Us Without Us: Federal Law No. 29, a Missed Opportunity}

The most prominent example of a missed opportunity to adequately and substantively engage persons with disabilities occurred in early 2006 when the UAE was considering the development of a comprehensive law addressing the rights of persons with disabilities. The newly formed Ministry of Social Affairs expeditiously sought persons with disabilities to share their thoughts. A common thread emerged throughout the three focus groups I conducted in October of 2009, namely that of a missed opportunity to demonstrate substantial engagement and participation. Persons with disabilities and their allies affirmed that the Ministry of Social Affairs did not substantively engage persons with disabilities in their drafting of a law for persons with disabilities. Their effort fell short. Participating with the Ministry of Social Affairs, according to one vocal participant, "was superficial 
and not real." Other participants mentioned they were frustrated that their comments were not incorporated and there was no follow-up on the meetings that were set. Even local government agencies and local officials were not informed of the pending law's announcement and local disabled leaders were not included in reading final drafts of the text.

After the law was declared and the press conferences settled, the Ministry of Social Affairs was to set out a work plan for the implementation of the federal law and was mandated to form national committees to identify priority areas and develop regulations. However, there was not sufficient ownership or engagement with other ministries or even with service providers across the emirate. Seven months after the law went into effect, one top official informed me during an interview that persons with disabilities would not participate in high-level committees implementing Federal Law No. 29 because there were no persons with disabilities in the UAE qualified to serve on such committees. ${ }^{6}$ Upon raising the issue of representation, he reconsidered his statement and asked me to connect him with qualified candidates. He was simply unaware that there were lawyers, doctors, and professors in the UAE who have disabilities. The next day, his office publicly announced that over $50 \%$ of the committee members should be persons with disabilities. ${ }^{7}$ However, even six years later, little was done to ensure persons with disabilities were actively engaged. The committees set up to implement Federal Law No. 29 had no budgets, power, or administrative support. The committees that would have had representation were in effect never fully activated.

\section{Community and Independent Living}

After living in the UAE for a few months, it became clear that the concept of independent living is foreign to the general population. Asma, a young woman who is a wheelchair user, indicated that she does not agree with Western notions of independence and shed light on a cultural dimension that I had ignored. During a private interview, she stated: "independent living sounds like a punishment, why can't I live with my family." Although some people with significant disabilities in the UAE are not able to imagine living their lives on their own terms with equal choices to the rest of the population, others yearn for it.

\footnotetext{
${ }^{6}$ Personal interview in April 2007 with a senior deputy in the Ministry of Social Affairs.

${ }^{7}$ Personal interview in May 2007 with a senior local-level government official.
} 
Hala's Story

Hasbrouck (2008a) wrote a column about a young local Emirati woman named Hala. She shares Hala's story to illustrate how Hala is empowered to live the type of life she has reason to value. Hasbrouck notes that Hala, instead of depending solely on help from her family, directs the time and manner of her care. By doing so, Hala develops enough self-confidence to pursue a career or start a family, knowing that she can meet all normal expectations with help from personal assistance services (Hasbrouck 2008a). Personal assistance services are common in the UAE as a large portion of the Emirati population has domestic workers. Domestic workers help with child care, housekeeping, errands, driving, and cooking (Hasbrouck 2008a). Domestic workers also provide support to disabled family members; however, the idea of a person with a disability directing their own care is still rather underdeveloped (Hasbrouck 2008a). In addition, a personal assistant could help with transportation and personal needs at school or work. In fact, by using personal assistance services, disabled Emiratis could meet all the social, economic, and civic responsibilities of daily life (Hasbrouck 2008b). Hasbrouck effectively argues that there are many Arab and Emirati pioneers with disabilities who like Hala have come to understand that the "disability" lies not with themselves but in "how society affects them." Thus, limiting beliefs affect the real choices people with disabilities have to live the type of life they have reason to value.

\section{Hussain's Story}

A young local Emirati with a neurological condition I met in August of 2010 exemplified the neglect and abuse that is perpetrated behind closed doors. I met Hussain at the Dubai Mall, a place where he says he can enjoy himself and meet friendly people. Hussain mentioned that he has a hard time meeting people because his life is different. He mentioned that his life is different because he is a person with a disability. He is treated differently and was taken out of school. He cried for two weeks when he was taken out of school because he lost his friends. Due to his disability, it was becoming increasingly difficult for him to read and neither his family nor his teachers provided any modifications to allow him to continue to be able to do so.

Shortly after he turned 15, his mother married him off to a Filipino woman whom he had never met. Due to his condition, he uses a wheelchair to get around and a diaper because he does not have aid to assist him 24 hours per day. The woman was to take care of him, but he soon realized 
that this was not really the case. She was, in fact, a servant for his mother. A year later, he was married to his second wife, this time against his will. $\mathrm{He}$ was then subsequently married to a third wife, again at the insistence of his mother. He cried for two months because he had not been given a choice and because he did not want to marry these women. Hussain has no voice and no choice in the affairs of his life. According to him, his mother makes all the decisions about his life and his three wives ridicule and mock him. He has no intimate relationships with any of the three wives and says that during family events he is usually marginalized. He said that his mother and wives do not respond positively when he asserts his wishes and tries to leave the house as much as possible because he cannot stand being there. Hussain is completely without recourse and assistance. His basic needs are met but he essentially has no freedoms. The prevalence of the rehabilitation or medical model of disability limits and counters the promulgation of a more modern "rights-based" model of inclusive education to take root. Hussain's story exemplifies what happens when the rights-based perspectives on disability are not protected, promoted, or enforced.

\section{Dana's Story}

The challenges facing persons with disabilities in Dubai are multi-faceted and counteract full social inclusion. In talking to locals who had disabilities, I understood that the traditional culture in Dubai limits the choices and freedoms of many groups, especially women, migrant workers, children, and the elderly, not just people with disabilities. To try and further understand the reality of options open to persons with disabilities in the city of Dubai, I asked some local friends the following question- "If the dominant culture does not even support a woman's choice to live independently, then how could a woman with a disability live independently and be included in the community, is this even possible in the UAE?" But despite the cultural and political challenges that are present, I was somewhat surprised to hear that they can.

Dana Nashawati is a Syrian national born in Dubai. She is blind and works at the Emirates Airlines customer service center answering phones. She goes to school at night and lives with a friend. She is active and has learned how to navigate the city on her own. Through the encouragement and support of her family, Dana has developed a strong sense of selfconfidence. She tells me that "the entire city is now in my head. I can get around and know where things are. The taxi drivers are so surprised when I tell them where to turn or how much farther or how much closer I want 
them to go before I get out. Sometimes people don't believe me when they find out I am blind." For Dana, living independently is clearly important, "I want to make my own choices, I want to be free and go where I want when I want without having to ask for any favors and Dubai's metro system now makes this easier." Dana's comments indicate that independent living is strongly affected by an ability to enjoy the services of the city on an equal basis with others, especially transport services.

\section{Marriage Fund for Independent Living}

The Marriage Fund was established in accordance with Federal Law No. 47 of 1992. It aims to encourage the marriage of citizens to other citizens, provide financial grants to citizens of limited means to help them to bear the costs of marriage, participate in achieving familial stability in society, and to conduct cultural, social, and behavioral awareness campaigns. The Fund is structured as a marriage incentive and also targets persons with disabilities. This fund gives grants of no less than 60,000 dirhams to the deserving among young Emirati adults (Emirates 2008, 22). The fund is also extended to persons with disabilities. According to the National Media Agency, two mass weddings for people with disabilities took place in the UAE. The Prime Minister Sheikh Mohammed bin Rashid presided over one of these mass weddings in 2008 and awarded each couple 70,000 dirhams to start their lives. These mass weddings allow people with disabilities a chance to advance into adulthood without the burden of organizing private wedding events, which can be cost-prohibitive for some families. Referencing the challenges to create an independent life in the community, Mohammed, a man with hearing impairment from Dubai, said, "We are a rich country and the government can do more. If you are married, the government gives you a house, but many disabled people do not marry, so it's tough for us." $\mathrm{He}$ continued by stating, "bad ideas toward people with disabilities prevent us from getting married, and we don't have the chance to work like others."

In 2009, Dr. Eman Gaad served as the Director for Disability Services and worked closely with Dr. Maryam Matar, the General Director of the Community Development Authority (CDA). They told me that social protection systems in Dubai need to focus on the needs of persons with disabilities and address issues of neglect, isolation, and segregation. On April 26, 2010, at the invitation of Dr. Matar and Dr. Gaad, I gave an hour-long lecture on living in the community to 40 key managers working at the CDA. The talk focused on bridging the gap between policy and practices, especially related to the issues that limit community and 
independent living. Participants asked questions about developing and measuring quality community-based services. According to Dr. Matar, CDA was a new entity tasked with creating a meaningful difference for persons with disabilities. ${ }^{8}$ The CDA works toward promoting and raising social standards in the local community and increasing the role of citizens in the community by cooperating with concerned entities in order to achieve the goals of the development sector and to develop the basic structures necessary for this. Since 2008, the CDA has worked to develop the programs, policies, and standards based on its five strategic goals: promotion of national identity; social protection; social inclusion; social empowerment; and social cohesion in Dubai. These areas continue to pose challenges to community integration. According to Dr. Gaad, this is due to strong family traditions that separate persons with disabilities from the rest of society due to a sense of shame. She said that disability has traditionally been viewed as a public shame and is only occasionally seen as something special. Participation is, therefore, primarily limited to adaptive sports and recreation. She stated optimistically that "this is changing, changing fast, but not quite as fast as I would like." Shame and social stigma create an altered understanding of the real choices people with disabilities have and the ways in which they can execute their basic functionings and freedom.

\section{Awareness Raising}

Shortly after I arrived in the UAE, I noticed the unique role the media played in stimulating public discussion. Freedom of speech and assembly is controlled and according to colleagues at the Dubai School of Government, the media is known to practice self-censorship. Disparaging remarks against the Ruler or the Ruler's family is prohibited by custom and according to a surprising decree issued in March of 2009, reports disparaging or threatening the economic security or economic standing of Dubai would be prosecuted. Within this context, the media serves a critical role in spreading awareness and ideas among the local and diverse expatriate populations as long as it does not directly criticize its leaders or their policies. From my own experience, I noticed that the media was very

\footnotetext{
${ }^{8}$ The CDA is a government entity founded in 2008 and mandated with enhancing the social development in Dubai to achieve the Dubai Strategic Plan 2015 that was announced by H.H. Sheikh Mohammed bin Rashid Al Maktoum on February 2007.
} 
interested in my research and during the six key months of my fieldwork (April-October 2009) I was interviewed ten times, appearing in seven English speaking newspaper articles and three English speaking radio segments. There were also over a dozen articles published about my research in both Arabic and English. This experience made me understand the interest and need in effectively engaging the media to promote, protect, and ensure the rights of persons with disabilities.

According to popular Emirati columnist, Sultan Sooud Al Qassemi, the media has become an unlikely ally in promoting disability as a rights issue. Sultan himself writes on contemporary economic, political, and cultural events in the UAE and has covered disability issues on occasion in his articles. He notes that it is a shame that there is, in general, a low degree of awareness about disability issues among the public and through our conversations between 2009 and 2013, he revealed his commitment to helping bring awareness to disability issues through his articles. Sultan understands well that the government signals its intent to the population and then generates buy-in through multiple channels of dialogue that include traditional media, social media, and the Ruler's council. These processes increase awareness and generate social discourse that shapes the nature of pending policies and programs.

\section{Mechanisms for Raising Awareness}

Staff writer, Ramona Ruiz, has written on disability rights issues for the National, the most widely circulated English-language daily in the UAE. She indicated that the human-interest stories linked to disability are usually presented positively in the English language media and tend to get widely read. The media analysis I conducted for this case study also tended to support her statement. My analysis of the local media included a review of over 300 English language newspaper articles published in the UAE between 2006 and 2010. The articles overwhelmingly indicate that the portrayal of persons with disabilities in the UAE media is relatively positive and often state that rights are being implemented and that incremental progress is being made.

Al Rifli is a young man with a visual impairment who hosts a youthfocused television program on a local Arabic-language channel. Through his work, he hopes he can do his part to change attitudes in Emirati society. Specifically, he wants to raise pressing social issues that young Emiratis face; one of these issues being the lack of understanding and opportunities for persons with disabilities. He acknowledges that persons with disabili- 
ties are seldom seen in public let alone hold jobs. According to him, "they just need to be given the chance" (Swan 2010). He notes that in the area of awareness raising, "The Government [is] trying to solve this problem and provide support." He stresses that most Emiratis with disabilities, "think that they can't do anything. They don't have the support to keep going. The family doesn't encourage them to live a normal life; they just keep them at home" (Swan 2010).

The lack of community awareness and involvement may also be a barrier to rehabilitation services for individuals with a disability in the community. The Dukmak (2009) survey results identified that parents' lack of awareness of rehabilitation services prevent children from being properly treated and an absence of campaigns on rehabilitation services or telephone hotlines to guide and advise parents limits the effectiveness and reach of the services. This, in turn, limits the effectiveness of the State in protecting the rights of children to access rehabilitation services. Dukmak (2009) argues that the lack of awareness could limit the provision of and subscription to family services. The lack of knowledge by parents about available services and lack of information with regard to resources can be eliminated according to Dukmak (2009) by increasing the visibility and accessibility of such services in community settings. Dukmak (2009) concludes that increased advertising and promotion should target consumers through pamphlets, newspaper, magazines, talks, and seminars (Dukmak 2009).

\section{How Models of Disability Shape Awareness Raising Efforts}

In 2009, a group of people with disabilities participated in a focus group that I was running at the Dubai School of Government. They stated that efforts to generate a substantive change in attitudes have been largely ineffective. Persons with disabilities wanted to see more sustainable measures to combat stereotypes, prejudices, and harmful practices relating to persons with disabilities and they wanted these efforts to reflect their direct experiences not related through an intermediary. However, a Deputy Minister that I spoke with at the Ministry of Social Affairs at the time would disagree. He noted that the Ministry had arranged public information campaigns and published journals on this topic and had been making great efforts to educate the public. One vocal focus group participant was a long-time advocate and disability rights campaigner named Haidar. Haidar, a wheelchair user stated that every public effort to raise awareness had been ineffective and suggested that one of the primary reasons for this was that most public awareness campaigns are not designed by or in coordination with persons with disabilities. Haidar eventually developed his 
own campaigns including riding a solar-powered wheelchair across the country to raise awareness.

Throughout every aspect of society, and through different channels, both negative and positive perceptions of persons with disabilities co-exist. However, another participant, Nada Al Bustami, stated that changes are indeed occurring: "Over the past ten years, things have really changed in terms of perception. The community is much more responsive, there is much more awareness, but negative stereotypes still persist." Awatif Ibrahim Akbari agreed, stating further that the negative and persistent stereotypes, prejudices, and harmful practices relating to persons with disabilities are not effectively combated. Focus group participants like $\mathrm{Nada} \mathrm{Al}$ Bustami shared cases where employers, school principals, or family members would continuously resist requests such as accessible toilets, extended time on exams, or simply the opportunity to form a family. The resistance exists on such occasions when an individual may want to assert his or her rights. These assertions come into conflict with dominant notions of who should be afforded rights and how those rights should be accommodated.

\section{Accessibility and Mobility}

After spending nearly six months in Dubai in 2009, I became increasingly concerned that there were no real experts that I could find that understood accessibility and usability of the built environment, ISO 21542:2011. I was delighted when I met Issasm El Aloui, a German-trained architect who recently moved to Dubai. During an interview he mentioned that "Dubai missed a unique opportunity to build a 21 st century city by not developing or enforcing building standards in the area of accessibility." El Aloui moved to Dubai in 2008 and was frustrated with the lack of clear guidelines on accessibility. He mentioned that "The entire building code in Dubai is 19 pages, and in Germany the codes to build only a bathroom are 200 pages." The lack of uniform standards characterizes Dubai's ad hoc approach to accessibility.

\section{Accessible Signage}

From my own experience noting signage on public buildings, I found a wide variety of different styles being used. Some buildings use simple, easy to understand signage. This is important not only for people with low vision or intellectual disabilities but also assists in the signage being more easily read by everyone. Implementing, promoting, and enforcing signage available in language and graphics that are easy to read and comprehend 
benefits the hundreds of nationalities and tourists that come through Dubai. Accessible signage, adequate degrees of color contrast, and signage in braille were present in all large public meeting facilities including malls, the metro, hotels, and conference centers.

\section{Training on Accessibility}

Although Dubai is a regional/global hub for tourism, finance, and services, there seemed to be no accessibility training programs in the Emirate of Dubai. This became increasingly clear when I organized a meeting with Tamdeen, a construction management company working on some of the biggest development projects in Dubai. Anwaar Al Shammari is the Director of Tamdeen and supervises the master planning of Dubai TECOM, Healthcare City, Academic City, Sports City, and Internet City, among others. Anwaar is also a recent graduate of architecture. She shared with me that neither she nor any of her colleagues received coursework or training on access issues. According to her, architecture programs in Dubai do not include access or universal design into the architecture curriculum. She added that the relevant stakeholders are not sufficiently trained on accessibility indicators and the government currently mandates no training. She had hoped that my research would illuminate some barriers or gaps that may be present in some of her own development projects since she and her colleagues did not have a clear idea of the accessibility requirements in master planning. I mentioned that there are opportunities to have such training provided by both the tertiary education system and private companies and consultants in the field of architecture and design. Ms. Al Shammari noted that without government enforcement, accessibility issues will not be acted upon.

\section{Transportation and Roads}

I had the chance to meet Mattar Al-Tayer, the Chairman of the Board and Executive Director of the Roads and Transport Authority (RTA), in May 2009 during an annual one-day conference on barrier-free tourism. Al-Tayer presented the Transport Strategy for People with Special Needs in Dubai in front of 50 professionals interested in lowering the physical barriers to Dubai's tourism infrastructure. Al-Tayer mentioned that the RTA had taken the lead in implementing Federal Law No. 29. He said this was accomplished by developing a comprehensive strategy to enhance 
accessibility in all modes of transportation (Al-Tayer 2009). Al-Tayer indicated that the RTA had conducted interviews with 259 persons with disabilities and found that of those interviewed, $80 \%$ were limited in their activities due to transportation system constraints. Additionally, the RTA study found that $95 \%$ of the interviewed respondents said that accessible transportation is important for a better quality of life (Al-Tayer 2009). On account of these findings, the RTA undertook a comprehensive approach to transportation accessibility. According to Jumana Nabti, a transportation planner in Abu Dhabi, "An inclusive transportation infrastructure is one in which accessibility was integrated into all aspects of work. Dubai realizes that it needs to make changes."

\section{Improving Mobility Through Human-Centered Design}

The RTA is responsible for the road network, as well as managing the transportation services in the Emirate. Tabitha Decker, an urban sociologist and visiting scholar at the Dubai School of Government, noted that the design of sidewalks and the existence of physical barriers in the city are problematic for persons with disabilities. In order to rectify this, the comprehensive RTA strategy began identifying the location of all physical barriers and established priority areas due for modification. In such areas, barriers would be removed and accessible design features would be implemented. The goal was to increase the total number of miles that are accessible and available to pedestrians, mothers with strollers, the elderly, and persons with disabilities. As Issasm El Aloui noted, "Access helps everyone in Dubai not just persons with disabilities." Jumana Nabti noted that Abu Dhabi had created a plan that was more comprehensive than Dubai but in the end, she stated both plans were aimed at the same goal; removing unnecessary barriers from the built environment (Fig. 5.1).

Between 2006 and 2013, I encountered insurmountable accessibility challenges all over Dubai. One prominent example was in Jumeirah Beach Road (JBR). JBR is a promenade lined with beachside shops and residences. The sidewalks contained a variety of obstacles that prevented me from enjoying the promenade on an equal basis with others. Barriers included protruding posts, a lack of curb-cuts, and uneven surfaces, among others. The beach runs parallel to Jumeirah Beach Road and I was happy to see that there was a mile-long boardwalk alongside the beach. When I 
Before

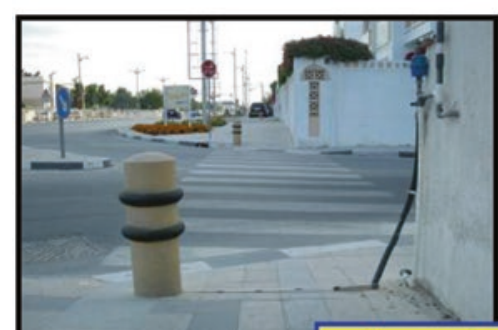

Removing obstacles
After
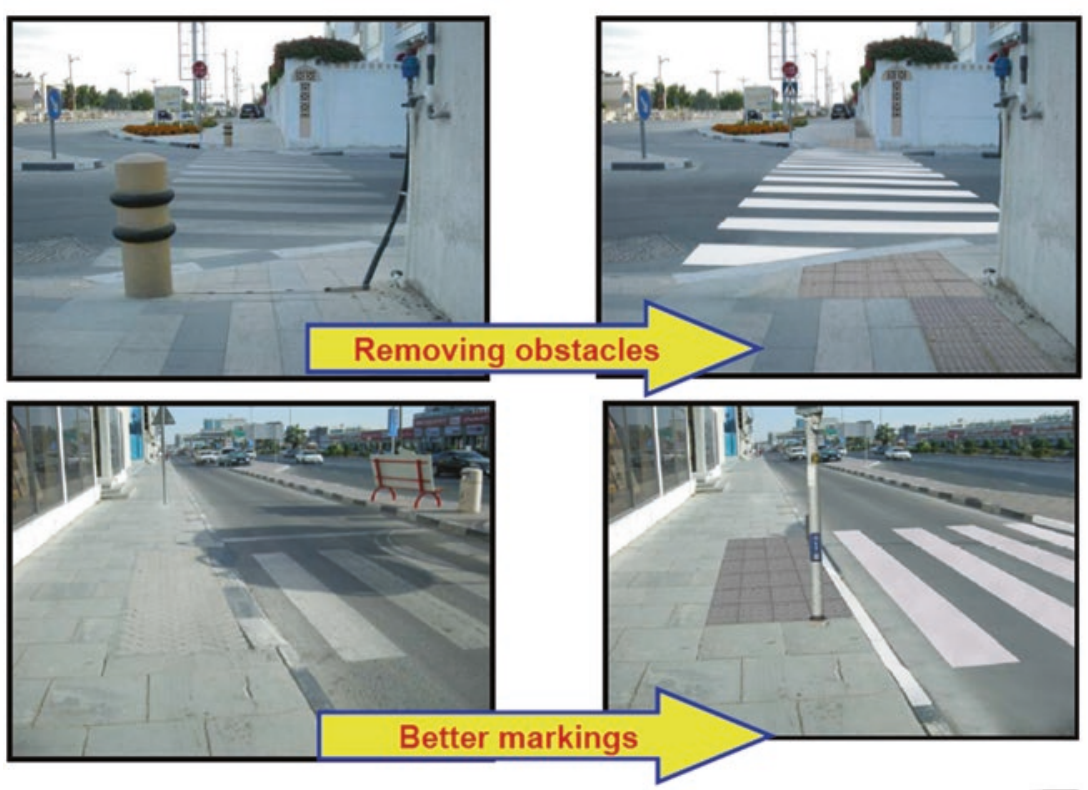

Fig. 5.1 Proposed changes as stipulated in the RTA's comprehensive Strategy for People of Determination; examples from Jumeirah Beach Road, Dubai

tried to approach the smooth cement boardwalk, I realized that there was no path to get to it, this boardwalk was surrounded by sand, limiting my ability to reach it and my ability to enjoy it.

In 2015, a 10-foot path was built that connected the sidewalk to the boardwalk and hence allowed wheelchair users an additional mile of accessible public infrastructure. Such gaps in planning and design could be caught in the future through the permitting process only if standards are put into place that stipulate that all public facilities should be made accessible on an equal basis to persons with and without disabilities. The RTA has already started this process and has presented some of the ways in which they will be identifying and modifying the built environment (Fig. 5.2). 
Before

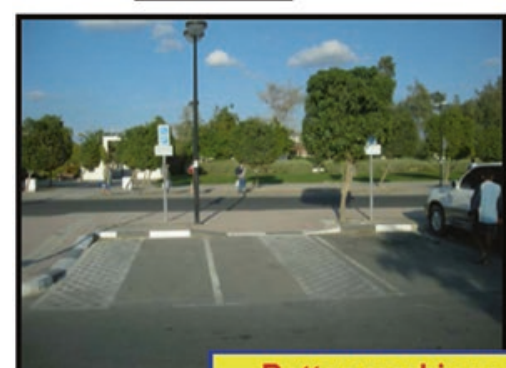

Better markings of spaces
After

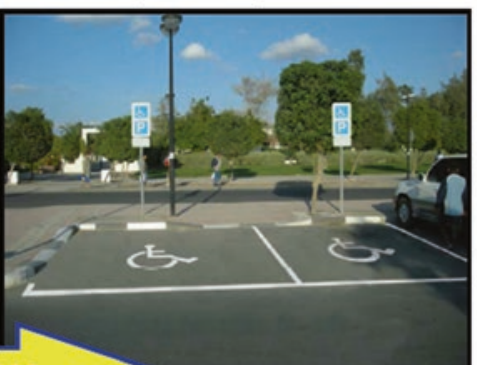

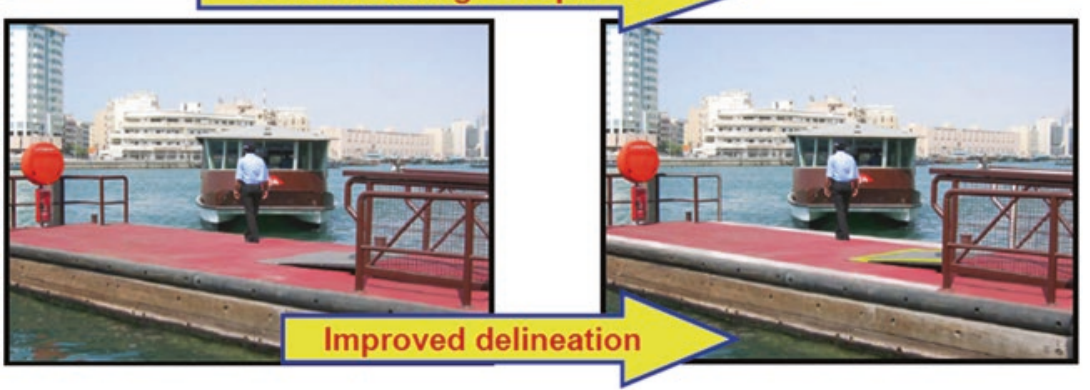

Fig. 5.2 Proposed changes as stipulated in RTA's comprehensive Strategy for People of Determination; examples show improved markings and delineations

\section{Public Metro and Public Buses}

In September of 2009, Dubai became the first city in the region to have an integrated public transport system fully accessible to people with disabilities. All modes of public transport (including the Dubai Metro, public buses, marine transport, and even some taxis) now meet the mobility requirements of the Road Transport Authority with respect to people with disabilities. After using both the bus system and the Dubai Metro, I realized that this system was indeed markedly superior to anything available in the region. ${ }^{9}$ The efforts put into this infrastructure to ensure ease of use have led to remarkable results (Fig. 5.3).

${ }^{9}$ I have visited the following countries in the region, Egypt, Lebanon, Saudi Arabia, Qatar, Oman, Yemen, Syria, and Kuwait. Dubai's transportation is also easier to use than the transportation systems that I have used in Paris and New York. 


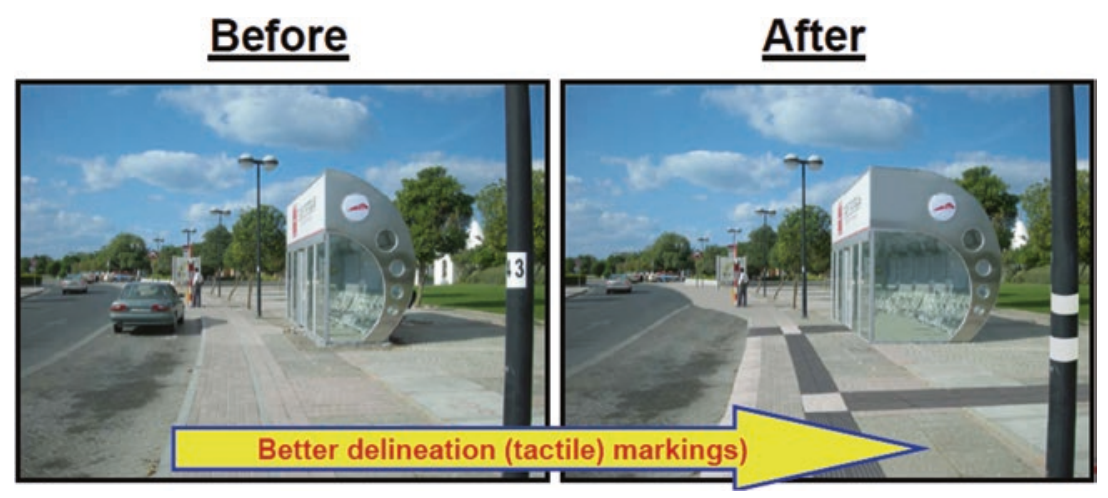

Fig. 5.3 Proposed changes as stipulated in RTA's comprehensive Strategy for People of Determination; examples of wider air-conditioned bus stops

According to Tabitha Decker, increasing access to transportation modes such as the Dubai Metro is important because it opens up the city to persons with disabilities. All of a sudden, they can access new places in new ways. Places that were off-limits are now on the map. Increasing efforts to map the accessible walking environments have been taken on by the RTA.

Challenges and barriers exist in the areas surrounding the bus and metro stops according to persons with disabilities who use the public transportation system in Dubai (Ahmed 2010). "Facilities for 'special passengers' are excellent within the stations and the trains but the access and exit areas on the roads need urgent improvement as they are dangerous for handicapped people," said Kaltham Obaid Bakheer Al Matroushi, Manager of the Ladies Section at Al Thiqah Club for the Handicapped (Ahmed 2010). Kaltham was among the 13 volunteers who were invited to participate in the study organized by the Rail Agency of the Dubai Roads and Transport Authority to identify gaps in the Metro's facilities (Ahmed 2010).

Badriya, a hearing-impaired teacher, suggested that at least one of the staff members at each station should be trained to deal with passengers who, like her, cannot hear. "It is difficult to communicate with the staff to seek any help or guidance," she said (Ahmed 2010). Abdul Redha Abu Al Hassan, Director of Rail Planning and Development at the RTA, said that the study aimed to further improve facilities for people with disabilities. He noted that the stations are designed with a "barrier-free access system" to make the metro accessible to all regardless of any physical impairment following best international practices (Ahmed 2010). 


\section{Dubai Taxi}

The RTA has purchased and runs a small fleet of three wheelchair accessible vehicles. Two of these vehicles were used between 2006 and 2009 in pilot programs testing different rates, fees, and dispatching systems. During my visits to Dubai, I have come to greatly depend on these vehicles and have been able to see that the RTA has adjusted their approach to this service over the years by changing from a fixed charge fee for pickups to regular metered fees. The vehicles have a steady demand from about 20 regular clients in Dubai. The taxis can travel to any emirate in the UAE and, like regular taxis, are also available for rental on a daily rate of $\$ 200$ per day. In August of 2010, the RTA purchased two additional accessible vehicles to add to its fleet. According to Mohammed, the senior of three "special" drivers, "The taxis are popular with tourists who use wheelchairs in Dubai" (Fig. 5.4).

\section{Live Assistance}

Dubai's position as a luxurious tourist destination gives it a unique advantage in terms of the availability of live assistance and intermediaries available to facilitate such things as opening doors, guiding customers through crowded areas, and so on. In this regard, Dubai also provides persons with disabilities with a unique and ample supply of live assistance in public places. During the months of March through October 2009, I noticed that such intermediaries, trained and untrained, were available to facilitate my own access to public buildings and facilities. Thus, it can be inferred that other persons with disabilities could greatly benefit from this unique characteristic of Dubai's tourism and leisure-based service sector. Live assistance afforded ease of access. Morad Ali Shadeed and Hussain

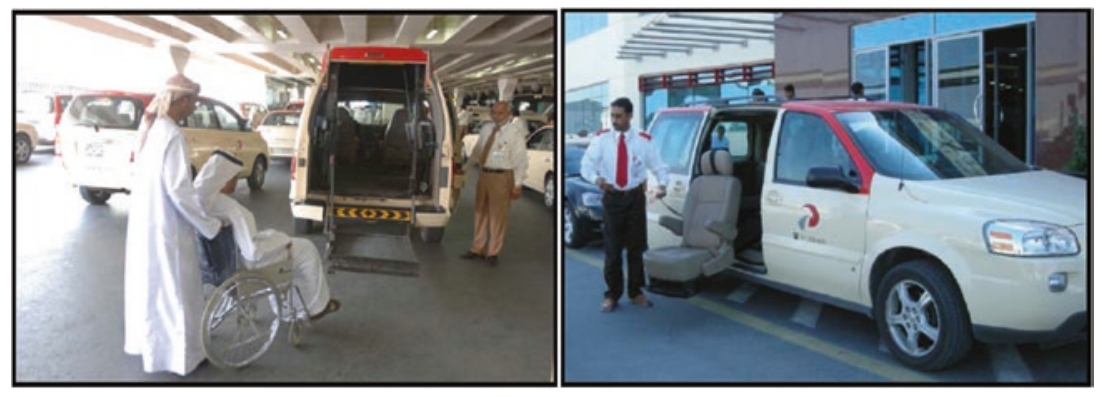

Fig. 5.4 Two of the five accessible vehicles owned and operated by the RTA 
Al Rahma, both wheelchair users, mentioned that there are always people available at the malls, hotels, or at restaurants to help with getting in and out of vehicles, buildings, residential or retail establishments, and airports.

\section{Access to Information}

During my time in the UAE speaking with numerous people about disability issues, it was clear that when talking about access, most people with and without disabilities failed to equate the concepts of equitable accessibility to information. Most often when speaking about accessibility, people primarily equate it to the provisions of accommodations in physical infrastructure such as ramps and elevators.

Information and Communications Technology (ICT) accessibility has become a key area of importance for cities around the world. As increasing volumes of information are stored and accessed online, it becomes vital that people can easily access this information whether they are at home or via mobile devices. This is of particular importance for persons with disabilities and the elderly, who often rely on access to information, such as public transport or city services information, to enable them to move around their cities and lead fulfilled lives away from their homes. Dubai, like other major cities around the world, has recognized the importance of this area and is making efforts to improve digital inclusion but also suffers from the common problem that many of these efforts remain separated from one another and lack a cohesive integration of efforts and services. Without accessibility standards, comprehensive planning, and careful guidance of these efforts, ICT programs risk leaving persons with disabilities further behind.

Between 2007 and 2013 I spoke with Fadi Salem, a researcher working at the Mohammed bin Rashid School of Government, formerly the Dubai School of Government about the technological shift taking place in Dubai. Dubai is positioned as a "leader in E-Government" however, he recognizes that ICT infrastructure does not currently take into account the needs of persons with disabilities. Abdullah Saeed Rashid Al Suwaidi, the Deputy Minister for Social Affairs, notes that the ministry has been working on improving this. He cites an example in the field of telecommunications where the Ministry of Social Affairs launched a project with Etisalat, the dominant telecommunication company in the UAE. The joint initiative would make telecommunication services accessible to the deaf by providing video calls where individuals could sign to each other and see the video feed in real time. This early engagement in the topic would later in 
2017 develop into digital accessibility standards for the emirate as well as an Emirate-wide initiative called Smart Dubai, which would require all government websites to comply with the WCAG AAA rating, the highest standard in digital accessibility.

\section{Mobility}

Dr. Hisham S. Farahat is the director of sales for Al Masood Mobility, a leader in the sale of mobility-related products. He affirmed that insufficient efforts have been made to promote the development of a comprehensive range of mobility products for persons with disabilities. He shared several stories of children who had lived their entire lives without mobility devices, developing greater medical complications and being denied the opportunity to leave their own home. He mentioned that most people were not aware of the range of mobility products that are currently sold in the UAE and the products that are available in the US, the UK, Japan, or Germany but not yet available in the UAE.

According to Dr. Farahat, persons with disabilities in Dubai do not have many opportunities to receive training in mobility skills. A notable exception to this is the Tamkeen Vocational Education Center for Individuals with Visual Impairments. More advanced or specialized assistive technologies are for the most part not available for persons with disabilities and are very expensive. Furthermore, very few centers exist that can provide assistive technologies such as customized wheelchairs, fitted prosthetics, electronic or environmental controls, automated door openers, or customized vehicles.

Federal Law No. 29 specifically forbids discrimination in obtaining a driving license for persons with disabilities. As a result, two of the 50 centers for instruction in driving are now offering specialized driving courses for drivers who as a result of paralysis or leg amputation may choose to use modified hand controls on their vehicles.

\section{Conclusion on Basic Functioning and Freedoms}

In regard to the provision of services that span health, rehabilitation, education, and employment for persons with disabilities, the period between 2006 and 2013 was notable for its lack of formulating a comprehensive and consistent approach. Teachers, parents, and persons with disabilities indicated that approaches were fragmented, and each school had a different level of readiness. 
Throughout my discussions, it was clear that there was a gap between what the public sector agencies said they were doing and the type of services and opportunities that children with disabilities and their parents actually received. This highlights the importance of advocating for and enforcing basic functionings to ensure the provisions outlined in Federal Law No. 29 are actually enforced and disability rights are achieved in the UAE.

This chapter also underscored the impact of participation and awareness on the ability of a society to create policies and implement plans that affect persons with disabilities that actually consult and include them in that process. Everyone should have the opportunity to participate in civil society and decision-making should include the consultation and leadership of those that the decisions most affect. When it comes to urban planning and ICT, persons with disabilities have a lot to gain but also a lot to lose from policies that ignore them entirely or do not adequately include them in their development.

Key to addressing these challenges is the development of strong awareness among the public of the effects that urban planning, policy, or design can have on the prospects for marginalized people in society to live independent and fulfilling lives. There is, however, evidence that attitudes in the UAE are shifting in a positive direction toward this greater awareness and understanding of how cities can be improved to benefit a greater number of people. As these attitudes continue to evolve and the built environment of the UAE continues to be transformed, greater freedoms for individuals will be realized. This will affect not only how people can make use of urban space but also directly affect the number of people able to actively participate in civil society, seek meaningful employment, and contribute to the cities in which they live.

\section{REFERENCES}

Ahmed, Ashfaq. "Dubai Metro's Accessibility Put to Special Needs Test.” Gulf News, 2010. http://dubaimetro.eu/featured/6157/dubai-metros-accessibilityput-to-special-needs-test.

Al-Tayer, Mattar. "RTA Transport Strategy for Special Needs in Dubai." Edited by Roads and Transport Authority, 2009, 1-37.

Bitar, Salaheddin. "The Rise and Decline of the Baath." Middle East International, no. 3 (1971): 12-15.

Dukmak, S. "Rehabilitation Services in the United Arab Emirates as Perceived by Parents of Children with Disabilities." Journal of Rebabilitation 75, no. 4 (2009): 27-34. 
Emirates, The United Arab, UAE Ministry of Foreign Affairs, and United Nations General Assembly. "National Report Submitted in Accordance with Paragraph 15 (A) of the Annex to Human Rights Council Resolution 5/1." Abu Dhabi: UAE Ministry of Foreign Affairs, 2008. http://www.ohchr.org/EN/ HRBodies/UPR/Pages/AESession3.aspx.

Hasbrouck, Amy. "Hala's Got a Good Job, a Social Life... and a Wheelchair." The National, no. April 25, 2008 (2008a): 4.

- "When a Man Is in Pain but the Law Blocks Treatment." The National, no. May 28, 2008 (2008b): 3.

Knowledge, and Human Development Authority (KHDA). "The Higher Education Landscape in Dubai 2014," 2014.

McMeans, Alison. "Disabled Children Live with Terror and Guilt." The National, no. May 15, 2010 (2010): 2.

Office, P M O, and UAE Federal Government. "National Strategy Brief." Dubai: Prime Minister's Office, 2006.

Sengupta, Arjun. "On the Theory and Practice of the Right to Development," Human Rights Quarterly 24, no. 4 (2002): 837-889.

- "The Human Right to Development." Oxford Development Studies 32, no. 2 (2004): 179-203.

Sengupta, Arjun, Archna Negi, and Moushumi Basu. Reflections on the Right to Development. Sage, 2005.

Swan, Melanie. "Blind Talk Show Host to Tackle Taboos." The National, no. February 13, 2010 (2010): 4.

Vizard, Polly, Sakiko Fukuda-Parr, and Diane Elson, "Introduction: The Capability Approach and Human Rights." Journal of Human Development and Capabilities 12 (2011): 1-22. http://www.tandfonline.com/toc/cjhd20/current.

Open Access This chapter is licensed under the terms of the Creative Commons Attribution 4.0 International License (http://creativecommons.org/licenses/ by $/ 4.0 /)$, which permits use, sharing, adaptation, distribution and reproduction in any medium or format, as long as you give appropriate credit to the original author(s) and the source, provide a link to the Creative Commons licence and indicate if changes were made.

The images or other third party material in this chapter are included in the chapter's Creative Commons licence, unless indicated otherwise in a credit line to the material. If material is not included in the chapter's Creative Commons licence and your intended use is not permitted by statutory regulation or exceeds the permitted use, you will need to obtain permission directly from the copyright holder.

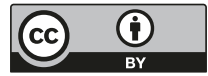

